\title{
PERANCANGAN KARAKTER VISUAL TRIBHUWANA WIJAYATUNGGADEWI
}

\author{
Nanda Agustia Fazri, Pujianto \\ Program Studi Desain Komunikasi Visual \\ Fakultas Bahasa Dan Seni, Universitas Indraprasta PGRI \\ Jl.Nangka 58 Tanjung Barat,Jakarta Selatan,Indonesia \\ ndagustiaf@gmail.com
}

\begin{abstract}
Abstrak
Tribhuwana Wijayatunggadewi mempunyai nama asli, yakni Dyah Gitarja. Ia adalah raja ke tiga Kerajaan Majapahit yang memerintah pada tahun 1328-1351. Perancangan karakter visual sosok Tribhuwana Wijayatunggadewi adalah untuk menjadi teladan kepada perempuan khususnya agar menjadi peribadi yang mempunyai perencanaan kehidupan kedepan agar hidupnya tertata dengan baik dan mempunyai wawasan yang luas, serta melakukan apapun dengan sungghsungguh dan bertanggung jawab. Metode studi pustaka, baik cetak seperti buku, maupun elektronik yaitu jurnal ilmiah, artikel, e-book, dan sebagainya. Penulis juga melakukan wawancara dan observasi berkaitan dengan watak dan karakter Tribhuwana dalam peran perluasan kekuasaan Majapahit. Berdasarkan data yang ada dan teori yang terkait dengan perancangan karakter visual. Hasil akhir perancangan karakter visual ini dapat menjadi refrensi ilmiah untuk perkembangan ilustrasi individu maupun kelompok untuk lebih percaya diri untuk lebih kreatif dan bersaing di pasar global sambil mempertahankan nilai - nilai budaya indonesia.
\end{abstract}

Kata kunci : Karakter, visual, Tribhuwana Wijayatunggadewi

\begin{abstract}
Tribhuwana Wijayatunggadewi has a original name, namely Dyah Gitarja. He was the third king of the Majapahit Kingdom who ruled twelfth until. The design of the visual character of Tribhuwana Wijayatunggadewi is to be a role model to women, especially to be a person who has life planning in the future so that his life is well organized and has broad insight, and does everything sincerely and responsibly. Literature study methods, both print such as books, and electronics, namely scientific journals, articles, e-books, and so on. The author also conducts interviews and observations relating to the character and character of Tribhuwana in the expansion role of Majapahit power. Based on available data and theories related to the design of visual characters. The final artwork of designing this visual character can It can be a scientific references for the development of individual and group to illustration more confidence for more creative and competitive in the global market while maintaining the value - the value of Indonesian culture.
\end{abstract}

Keywords: Character, visual, Tribhuwana Wijayatunggadewi

\section{PENDAHULUAN}

Kerajaan Majapahit merupakan kerajaan hindu tertua di tanah jawa. Setelah kematian Raden Wijaya, pemerintahan Kerajaan Majapahit dilanjutkan oleh anaknya, yakni Jayanagara. Jayanagara akhirnya meninggal di tanggan tabibnya sendiri (adji, 2013). Rajaputri Tribhuwana Tunggadewi sebenarnya tidak pernah terpikir naik takhta sebagai pemimpin Kerajaan Majapahit. 
Ia hanya mematuhi titah sang ibunda, Gayatri, dan memang karena tidak ada keturunan laki-laki lain sepeninggal Jayanegara. Demi baktinya kepada sang ibunda, Tribhuwana Wijayatunggadewi bersedia menjadi ratu menggantikan Jayanegara.

Bertanggungjawab dalam menjalankan pemerintahan, Kebijaksanaan Tribhuwana dalam mengambil keputusan saat menggangkat Gajah mada menjadi Mahapatih, berani turun dan terlibat langsung dalam memadamkan pemberontakan.

Memutuskan turun takhta pada 1350. Keputusan tersebut diambil seiring wafatnya Gayatri Rajapatni, Yakni ibunda dari Tribhuwana Wijayatunggadewi. Bagi Tribhuwana Wijayatunggadewi, singgasana Majapahit sebenarnya adalah hak sang ibunda yang memberinya kuasa untuk menjadi pemimpin. Maka itu, setelah Gayatri tiada, Tribhuwana Wijayatunggadewi menganggap bahwa amanat sang ibunda telah ditunaikannya, dan ia merasa tidak berhak lagi menjadi penguasa meskipun saat itu Majapahit tengah merintis pamor sebagai kerajaan yang digdaya (Raditya, 2017).

Takhta Majapahit selanjutnya diserahkan kepada putra mahkotanya, yakni Hayam Wuruk. Tribhuwana Wijayatunggadewi sendiri kemudian menempati posisi sebagai salah satu anggota Saptaprabhu, semacam dewan pertimbangan agung yang beranggotakan keluarga kerajaan. Tribhuwana Wijayatunggadewi, juga Gajah Mada, mendampingi Hayam Wuruk mengelola pemerintahan.

\section{METODE PENELITIAN}

Penulis menusun artikel ini mengunakan Metode studi pustaka, baik cetak seperti buku, maupun elektronik yaitu jurnal ilmiah, artikel, e-book, dan sebagainya. Penulis juga melakukan wawancara dan observasi berkaitan dengan watak dan karakter Tribhuwana dalam peran perluasan kekuasaan Majapahit.

\section{HASIL DAN PEMBAHASAN}

\section{Sosok Tribhuwana Tunggadewi}

Sri Tribhuwana Tunggadewi Maharajasa Jayawisniuwardhani nama aslinya adalah Dyah Gitarja, Putri pertama mendiang Raden wijaya dan Dyah Gayatri Rajapatni.Menurut catatan sejarah sejak kematian Jayanegara dibutuhkan waktu selama setahun untuk menunjuk siapa yang berhak menjadi ratu Majapahit. Sesuai dengan aturan silsilah kerajaan, yang berhak menggantikan Sri Jayanegara sebagai raja adalah saudaranya, salah satu dari putri Sri Gitarja dan Dyah Wyat. Sebelum pilihan dijatuhkan ke salah satunya, kekuasaan masih dipegang di tangan Ratu Gayatri, istri mendiang Raden Wijay dan akhirnya memberikan tahta tersebut kepada Tribhuwana wijayatunggadewi.

Rajaputri Tribhuwana Tunggadewi sebenarnya tidak pernah terpikir naik takhta sebagai pemimpin Kerajaan Majapahit. Ia hanya mematuhi titah sang ibunda, Gayatri, dan memang karena tidak ada keturunan laki-laki lain sepeninggal Jayanegara. Demi baktinya kepada sang ibunda. Tribhuwana Wijayatunggadewi bersedia menjadi ratu menggantikan Jayanegara dan Tribhuwana Wijayatunggadewi menjalankan perintah ibunya dengan penuh tanggung jawab terbukti dengan strategi - strategi politiknya yang Ia terapkan dalam pemerintahannya, Tribhuwana Wijayatunggadewi juga turun dan terlibat langsung memimpin pasukan untuk memadamkan pemberontakan di Sadeng dan Keta, berlaku bijaksana akan Gajah mada yang sudah mengabdi kepada kerajaan dan menggangkat gajah mada menjadi Mahapatih untuk mendampinginya. Tribhuwana adalah sosok yang mempunyai karakter tegas, bijaksana dan karakteristik cantik serta anggun.

Menurut (Munandar, 2018) para pejabat keraton memakai kain bercorak, yakni Motif sulur Grising ,surya kawung dan Parang. Aksesoris yang dipakai oleh Ratu atau Rajaputri, yakni kalung, Gelang, gelang lengan atau kala arband, Rantai emas, Mahkota, Mahkota dari gulungan rambut yang tinggi, kemudian senjata yang digunakan adalah patrem semacam keris namun ukurannya lebih kecil, serta jama. Semakin banyak perhiasan yang dipakai maka menyimbolkan kedudukannya di dalam Kerajaan. 
Salah satu cirinya yang kuat adalah terdapatnya garis-garis di sekitar tubuh arca. Garis ini sebagai garis sinar yang lazim disebut dengan "sinar Majapahit". Adapun bentuk relief lingkaran yang dilengkapi dengan garis-garis sinar seringkah didapatkan di beberapa bagian candi yang disebut dengan "Surya Majapahit".

Dalam artikel yang ditulis oleh (munandar, 2009) N.J. Krom pernah mengemukakan dalam artikelnya yang berjudul "De bellden van Tjandi Rimbi" (1912) tentang ciri-ciri arca masa Majapahit sebagai berikut:

1. Pada kedua sisi arca dihias dengan padma yang ke luar dari pot/vas bunga.

2. Hiasan kepala (mahkota) berbentuk kerucut (kirita makuta) dan terdapat pula ikat kepala di dahi (jamang).

3. Perhiasan telinga berbentuk memanjang(sumping) Gerai rambut dihias dengan makara atau perhiasan lain yang sesuai.

4. Tubuh bagian atas terbuka (tidak memakai pakaian) kecuali perhiasan tali dada atau tali kasta (upawita).

5. Terdapat ikat pinggang di bawah dada (anteng).

6. Digambarkan mengenakan kain sarung berlapis-lapis.

7. Ikat pinggang setinggi perut, di bawahnya terdapat lipatan kain yang terlihat. Selain itu, dibawah lipatan terdapat ujung tali yang menggantung di bahu kiri.

8. Pada kedua kaki menjuntai tali-tali dari ikat pinggang setinggi perahu dan di ujung tali terdapat hiasan.

9. Wiru dari kain pada kedua sisi tubuh dan di antara dua kaki, ujungnya terbelah berbentuk ekor burung layang-layang.

10. Memakai gelang tangan, kelat bahu dan gelang kaki yang lebar

Hal yang perlu diperhatikan adalah bahwa tidak semua ciri arca tersebut dapat secara lengkap dijumpai pada setiap arca masa Majapahit. Ciri-ciri tersebut hanya hadir pada beberapa arca penting saja, seperti arca Hari-Hara dari Candi Sumberjati, arca Parwati dari Candi Ngrimbi. Berdasarkan data yang ada candi Parwati ini adalah pendharmaan dari Rajaputri Tribhuwana Wujayatunggadewi.

\section{Proses Perancangan \\ Ilustrasi}

Gambar maupun ilustrasi merupakan elemen penting dari sebuah buku. Gambar dapat menjadi pintu gerbang bagi pembaca untuk masuk ke dalam konten buku yang hendak disampaikan. Oleh karena itu perlu pertimbangan yang matang baik dalam memilih gambar maupun cara menampilkannya. Gambar yang baik harus dapat mendeskripsikan artikel yang disampaikan secara, cepat dan efektif, relevan dengan konteks yang disampaikan, memiliki makna yang dalam, dan dapat mempengaruhi emosi

Ilustrasi adalah seni gambar yang digunakan untuk memberi penjelas atas suatu maksud atau tujuan secara visual. Dalam perkembangannya,ilustrasi secara lebih lanjut ternyata tidak hanya berguna sebagai sarana pendukun cerita, tetapi dapat juga menghiasi ruang kosong menjadi lebih indah untuk diliha dan dirasakan oleh pancainndera manusia (Kusrianto, 2007) .

\section{Warna}

Warna merupakan unsur desain yang paling menonjol, dengan adanya warna menjadikan suatu benda dapat dilihat, selain itu warna juga dapat mengungkapkan perasaan atau watak benda yang di rancang. Warna dapat menunjukan sifat yang beda-beda, bahkan mempunyai variasi yang sangat banyak yaitu warna muda, warna tua, warna gelap, warna terang, warna redup, warna cemerlang. Sedangkan dilihat dari sumbernya, ada warna merah, biru, kuning, hijau, orange dan lain sebagainya. Tetapi jika disebut warna panas, warna dingin, warna lembut, warna ringan, warna sedih warna gembira, dan sebagainya maka ini disebut juga dengan watak warna Berdasarkan pemaparan di atas dari beberapa sumber dapat di simpulkan bahwa unsur desain 
merupakan unsur dari garis, arah, bentuk, ukuran, tekstur, sifat gelap terang dan warna yang di kombinasikan untuk mendapatkan hasil yang sempurna dalam pembuatan desain sehingga mudah di pahami semua orang (Ernawati, Izwerni, dan Nelmira, 2008).

1. Hitam adalah warna tanah, berkaitan dengan sifat aluamah Dalam masyarakat Jawa, warna ini dapat diartikan sebagai keabadian dan kekuatan.Mencerminkan keberanian, pusat perhatian (terutama lawan jenis) ketenangan, dan dominasi keteguhan, kekuatan dan keteguhan hati, lebih menyukai yang alami daripada yang palsu.

2. Kuning emas secara umum, warna terang seperti halnya kuning, memberikan kesan tenang, bahagia, energik, dan rasa optimis. Adapun penggunaan warna kuning pada ruangan dipercaya mampu merangsang aktivitas pikiran dan mental, bahkan berdampak pada meningkatnya kemampuan analisis seseorang. Warna Kuning Emas, bermakna jiwa kepeloporan (Kasiyan, 2013).

Menurut (Pratama, Wardani and Akbar, 2018) Unsur - unsur visual dari garis , bentuk, tekstur dan warna dapat menghasilkan ekpresi, postur, kostum, dan aksesoris yang memberikan gambaran tertentu untuk karakter . pada elemen visual tekstur pakaian menunjukkan tekstur terlihat dalam motif batik dan bentuk perhiasan emas jawa. Pada elemen aksesoris esrns emas melambangkan bangsawan.

Batik Sulur Gringsing dikenakan oleh raja kerajaan. Dalam Kitab Negarakertagama dan Serat Pararaton, batik motif gringsing menjadi motif batik tertua dengan ciri khas yang memiliki pusat atau yang disebut dengan sedulur papat lima pancer. Struktur tersebut bisa berkembang sesuai kelipatannya menjadi delapan dengan satu pusat dan seterusnya. Selain itu juga terdapat semacam simbol berupa lingkaran atau bulatan dengan titik di tengahnya.

Batik Gringsing memiliki filosofi yaitu keseimbangan, kemakumuran dan kesuburan. Warna yang digunakan pada batik gringsing sangat beragam, ada yang berwarna gelap, sedang atau warna yang muda. Ada yang hanya terdiri dari warna cokal dan hitam saja, dan ada juga yang terdiri dari beberapa warna. Sebagai batik kuno, batik gringsing menggunakan warna alam. Pewarnaan alam tertua adalah Indigo (biru) dan Kesumba (merah). Dalam proses pewarnaannya, pewarna alam itu diikat melalui proses fiksasi agar tidak luntur. Cara fiksasinya menggunakan tawas, air kapur, atau batu ijo.

\section{Perancangan karakter visual Tribhuwana Wijayatunggadewi}

Berdasakan data diatas dapat dijadikan dasar perancangan desain karakter Tribhuwana Wijayatunggadewi dan perancangan tersebut pula mengacu pada jurnal artikel yang di buat oleh (Pratama, Wardani and Akbar, 2018) menjadi referensi dalam perancangan karakter visual dari Tribuwana Wijaya tunggadewi.

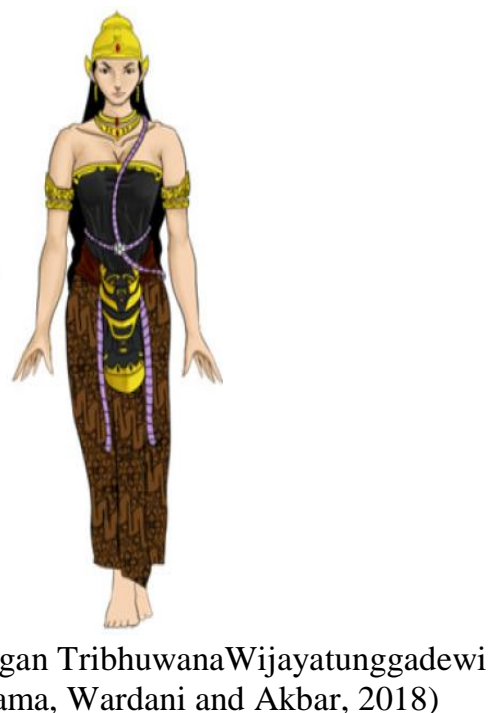

Gambar1 Perancangan TribhuwanaWijayatunggadew
Sumber : (Pratama, Wardani and Akbar, 2018) 
Adapun ini adalah desain atau penggayaan karakter Tribhuwana Wijayatunggadewi oleh (Pratama, Wardani and Akbar, 2018).

Berdasarkan data dan referensi karya sebagai acuan dalam perancangan untuk menjadi tolak ukur dalam pembuatan karakter tokoh tersebut yakni Tribhuwana wijayatunggadewi berikut adalah deksripsi dari perancangan yang dibuat oleh (Pratama, Wardani and Akbar, 2018) karakter visual dari Tribhuwana ini melalui garis wajah dan tubuh yang merepresentasikan sosok yang menunjukan keseriusan, kekuatan, dan konsisten. Kemudian pada bentuk tubuh mereprenstasikan kaakter yang positif, kekuatan, dan rasionalitas, serta busana yang digunakan menunjukkan tekstur terlihat dalam motif batik dan bentuk perhiasan emas jawa kuno. Cantik dan kelembutan ekspresi wajah juga sebagai keanggunan dan sikap kewanitaan.

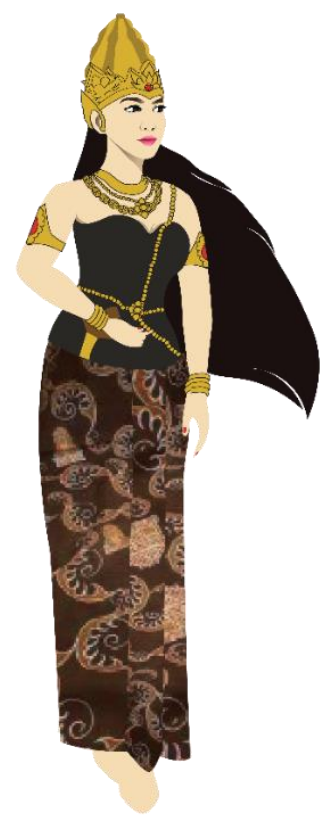

Gambar2 Perancangan Tribhuwana Wijayatunggadewi

(Dokumentadi pribadi)

Karakter yang di buat berdasarkan rujukan dari jurnal yang membahas perancangan karakter visual novel (Pratama, Wardani and Akbar, 2018) yaitu: Karakter tribhuwana ini dibuat berdasarkan data yang ada dengan style vector sehingga dapat mendekati penggambaran aslinya . pada karakter visual ini Tribhuwana mengenakan mahkota yang (berbentuk) kerucut, kemudian menggunakan tiga kalung, dikarenakan menurut (Munandar, 2018) memaparkana bahwa semakin banyak menggunakan perhiasan maka menyimbolkan derajat di dalam kerajaan Majapahit, llu penggunaan kemben adalah guna memberikan estetika dalam ilustrasi agar layak untuk di terima. Dikarenakan menurut N.J. Krom dalam (Munandar, 2009) ciri candi perwujudan raja raja di Majapahit yaitu terutama Tribhuwana Wiajyatunggadewi yang menurut kertanagara di dharmakan di arca Dewi parwati yang berada di candi Rimbi. Kemudian menggunakan motif sulur grising, yakni batik yang digunakan hanya khusus raja-raja, pemakaian kelat bahu, upawita, gelang serta rambut yang dibuarkan menjuntai kebelakang menampilkan sosok kebangsawanan dan derajatnya. Berdasarkan kajian pustaka yang mendasari penciptaan karakter visual, maka tujuan dari penelitian ini adalah untuk memberikan referensi, inspirasi, serta mendorong pengembangan produk kreatif digital yang mempromosikan nilai-nilai budaya lokal, termasuk melalui pembentukan karakter visual.

\section{SIMPULAN}

Desain karakter visual selanjutnya dapat mendorong lebih mewakili tokoh sejarah dan membawa pesan budaya. Studi desain visual karakter dapat menjadi refrensi ilmiah untuk 
perkembangan ilustrasi individu maupun kelompok untuk lebih percaya diri untuk lebih kreatif dan bersaing di pasar global sambil mempertahankan nilai - nilai budaya indonesia.

Karakter visual Tribhuwana Wijayatunggadewi ini menggunakan bentuk ilustrasi dekorasi, kartun dan ilustrasi khayalan, sehingga membawa suasana santai dan nyaman bagi pembaca. Ilustrasi karakter berwarna yang terutama dibuat dengan pena dan tinta hitam maupun cat air, lalu kemudian dilanjutkan dengan komputer menggunakan program pendukung seperti adobe illustrator.

\section{DAFTAR PUSTAKA}

Adji, B. K., (2013). Majapahit: Menguak Majapahit berdasarkan fakta sejarah. Yogyakarta: aksara.

Munandar, A. A. (2009). Majapahit Dalam Sejarah [2]. Diakses dari http://phdi.or.id/artikel /majapahit-dalam-sejarah-2

Raditya, I. N. (2017). Takhta Majapahit dan Bakti Tribhuwana Tunggadewi Kepada Ibu. Diakses dari https://tirto.id/takhta-majapahit-dan-bakti-tribhuwana-tunggadewi-kepada-ibu-cB9k

Kusrianto, A. (2009). Pengantar desain komunikasi visual. Yogyakarta: Penerbit Andi.

Kasiyan. (2013). Nirwana warna. Diakses dari http://staffnew.uny.ac.id/upload/132243650 /pendidikan/Nirwana+Dwimatra+Warna.pdf 